\title{
Evidence of increased islet cell proliferation in patients with recent-onset type 1 diabetes
}

\author{
A. Willcox • S. J. Richardson • A. J. Bone • \\ A. K. Foulis • N. G. Morgan
}

Received: 9 February 2010 /Accepted: 12 May 2010/Published online: 9 June 2010

(C) Springer-Verlag 2010

\begin{abstract}
Aims/hypothesis In adults, the rate of beta cell replication is normally very low, but recent evidence suggests that it may increase during insulitis. We therefore studied tissue from donors with recent-onset type 1 diabetes to establish whether islet cell proliferation is increased during the disease process.

Methods Paraffin-embedded pancreatic sections from ten donors with recent-onset type 1 diabetes and a range of relevant controls were stained by immunohistochemical techniques with antibodies against the proliferation markers Ki67 and minichromosome maintenance protein-2 (MCM-2). A combination staining technique involving immunoper-
\end{abstract}

Electronic supplementary material The online version of this article (doi:10.1007/s00125-010-1817-6) contains supplementary material, which is available to authorised users.

\footnotetext{
A. Willcox $\cdot$ N. G. Morgan $(\bowtie)$

Institute of Biomedical and Clinical Science,

Tamar Science Park, Derriford,

Plymouth PL6 8BU, UK

e-mail: noel.morgan@pms.ac.uk

\section{S. J. Richardson}

Institute of Biomedical and Clinical Science,

Peninsula College of Medicine and Dentistry

(University of Plymouth),

Plymouth, UK
}

Peninsula College of Medicine and Dentistry (University of Exeter),

\section{A. J. Bone}

School of Pharmacy and Biomolecular Sciences,

University of Brighton,

Brighton, UK

\author{
A. K. Foulis \\ Department of Pathology, Glasgow Royal Infirmary, \\ Glasgow, UK
}

oxidase and immunofluorescence methods was developed to quantify the numbers of alpha and beta cells with Ki67positive nuclei and to investigate the relationship between insulitis and islet cell proliferation.

Results In non-diabetic control donors, only $1.1 \pm 0.3 \%$ (mean $\pm \mathrm{SEM}$ ) of islets contained one or more $\mathrm{Ki}^{+} 7^{+}$islet cells, whereas this proportion was increased markedly in recent-onset type 1 diabetes $(10.88 \pm 2.5 \% ; p<0.005)$. An equivalent increase in $\mathrm{Ki}^{+} 7^{+}$staining occurred in alpha and beta cells and was correlated positively with the presence of insulitis. A significant increase in the labelling of islet cells from type 1 diabetic donors was also seen when MCM-2 staining was employed. Increased islet cell proliferation was not evident in three donors with longer duration type 1 diabetes or in ten type 2 diabetic donors. Conclusions/interpretation Alpha and beta cells undergo a marked increase in proliferation during the progression of type 1 diabetes in humans. The results imply that islet cell proliferation is re-initiated in response to the autoimmune attack associated with type 1 diabetes.

Keywords Alpha cell $\cdot$ Beta cell $\cdot$ Human . Immunohistochemistry $\cdot$ Insulitis $\cdot$ Ki67 $\cdot$ Minichromosome maintenance protein 2 . Proliferation - Type 1 diabetes

\author{
Abbreviations \\ G Gap (in cell cycle) \\ MCM-2 Minichromosome maintenance protein 2
}

\section{Introduction}

Type 1 diabetes is a T cell-mediated autoimmune disease in which the insulin-secreting beta cells of the islets of Langerhans are destroyed selectively [1]. Clinical symptoms 
arise when $\sim 70 \%$ of the total beta cell mass is lost, a process that follows a relatively protracted time course (months to years), during which the net rate of cell loss must exceed the rate of beta cell replacement [2].

Beta cell proliferation has been studied to only a limited extent in humans, but the available evidence implies that this process occurs at relatively high levels during the first 2 years of life and declines rapidly thereafter [3, 4]. However, it is also clear that, at least in animals, beta cell proliferation can be re-induced in adulthood under conditions when insulin resistance is increased, for example during pregnancy or in obesity [5-7]. This suggests that beta cells may retain an intrinsic capacity to replicate, but that they become largely quiescent during early childhood.

Recent evidence from a single case report [8] has revealed that enhanced proliferation of beta cells occurred in an adult human who was characterised as 'prediabetic' by virtue of the presence of circulating islet autoantibody positivity and active insulitis on histological examination of the pancreas. This proliferative response was observed prior to the onset of clinical symptoms, thereby raising the possibility that a compensatory increase in beta cell proliferation may occur early in the development of type 1 diabetes in humans. This would be consistent with evidence from animal models, where enhanced beta cell proliferation has also been seen early in the disease process [9-11], but this evidence differs from the conclusions of Butler et al. [12], who did not detect enhanced beta cell replication in pancreas sections recovered from a cohort of newly diagnosed type 1 diabetic patients. It is important, therefore, to clarify whether enhanced beta cell proliferation occurs during the course of human type 1 diabetes. If this were to be the case, then it might offer a window of opportunity for therapeutic intervention to replenish beta cell mass, in parallel with attempts to limit the rate of autoimmune-mediated cell loss. One recent study reported the detection of insulin-positive cells in 88\% (37/42) of patients with long-standing type 1 diabetes, suggesting a potentially substantial window of opportunity for intervention with potential regenerative therapies [13].

To address this issue more fully, we analysed pancreatic tissue from a cohort of patients with recent-onset type 1 diabetes. Two independent markers of cell proliferation were studied using both light and fluorescence microscopy to identify and quantify proliferating endocrine cells.

\section{Methods}

Participants We selected ten human pancreases recovered from deceased patients with recent-onset type 1 diabetes (disease duration $\leq 18$ months) who are members of a cohort that has been used previously [14].
Selection was achieved randomly, except that specimens post-fixed in mercuric chloride were excluded, as this fixative has proven unsuitable for labelling with certain antibodies. The specimens used had been fixed in buffered $p$-formaldehyde, unbuffered formol saline or Bouin's fixative, and were all paraffin-embedded. Of the ten pancreases, nine were removed at autopsy (D1-D9) and one was recovered at the time of organ donation (D10). Nine of the patients were in the age range 1 to 23 years (mean 10.9 \pm 2.4 ). One female patient was 42 years old, raising the overall mean to $14 \pm 3.8$ years (Table 1). As controls we also studied pancreatic specimens from donor groups as follows: (1) 14 non-diabetic (ten of which were paediatric $[\mathrm{C} 1-\mathrm{C} 10]$ and four of which were adults [C11C14]; surgical specimens, healthy regions utilised); (2) ten type 2 diabetic donors (C15-C24); (3) three donors with long-duration type 1 diabetes (C25-C27); (4) 12 patients with pancreatitis (nine of which were chronic [C28-C36], two autoimmune [C37-38] and one obstructive [C39]); and (5) nine non-diabetic donors who were age-matched with the type 2 diabetic donors (C40-C48). Full details are listed in Electronic supplementary material (ESM) Table 1. Sections of human tonsil and pancreatic lymph node were used as positive control tissues for markers of cell proliferation. The current investigation was performed with full ethical approval from the Research Ethics Committee, Glasgow Royal Infirmary, Glasgow, UK.

Immunohistochemistry Serial sections $(4 \mu \mathrm{m})$ were mounted on glass slides coated in (3-aminopropyl)-triethoxysilane (Sigma Aldrich, Poole, UK). Sections were processed and labelled using a standard immunoperoxidase technique for paraffin sections. Heat-induced epitope retrieval was performed by heating the sections in a pressure cooker and in a microwave oven on full power $(800 \mathrm{~W})$ for $20 \mathrm{~min}$, followed by $20 \mathrm{~min}$ of cooling at room temperature. EDTA ( $1 \mathrm{mmol} / \mathrm{l}$; Sigma Aldrich) buffer, $\mathrm{pH}$ 8.0, was used to unmask Ki67 and $10 \mathrm{mmol} / \mathrm{l}$ citrate (Sigma Aldrich) buffer, $\mathrm{pH}$ 6.0, was used for minichromosome maintenance protein 2 (MCM-2). Details of all primary antibodies are listed in Table 2. Sections were incubated for $1 \mathrm{~h}$ in primary antibody at room temperature. A detection system (REAL Envision; Dako) was used for antigen detection. Sections were counterstained with haematoxylin (Dako). Some slides were processed in the absence of primary antibody or with isotype control antisera to confirm the specificity of labelling.

Combined immunoperoxidase and immunofluorescence immunohistochemistry A combination technique was used, in which sections were dual-stained using the immunoperoxidase technique described above, followed by immunofluorescence labelling of the same sections. Anti-Ki67 and 
Table 1 Details of donors with recent-onset type 1 diabetes

\begin{tabular}{|c|c|c|c|c|c|c|c|c|c|}
\hline Patient & Age (years) & Sex & $\begin{array}{l}\text { Duration of } \\
\text { diabetes }\end{array}$ & Cause of death & Islets $(n)$ & Ki67+ islets $(n)$ & ICIs $(n)$ & $\begin{array}{l}\text { ICI with } \\
\text { insulitis }(n)\end{array}$ & $\begin{array}{l}\text { IDI with } \\
\text { insulitis }(n)\end{array}$ \\
\hline D1 & 1 & $\mathrm{~F}$ & 3 days & Ketoacidosis & 149 & 11 & 10 & 10 & 21 \\
\hline D2 & 4 & $\mathrm{~F}$ & 3 weeks & Ketoacidosis & 132 & 16 & 32 & 22 & 5 \\
\hline D3 & 6 & $\mathrm{~F}$ & $<1$ week & Ketoacidosis & 37 & 4 & 29 & 10 & 0 \\
\hline D4 & 7 & $\mathrm{~F}$ & $\begin{array}{r}\text { Unspecified } \\
\text { but recent }\end{array}$ & Ketoacidosis & 90 & 8 & 42 & 3 & 2 \\
\hline D5 & 11 & $\mathrm{~F}$ & 5 days & Ketoacidosis & 132 & 14 & 30 & 26 & 15 \\
\hline D6 & 13 & M & 2 days & Ketoacidosis & 86 & 7 & 21 & 14 & 2 \\
\hline D7 & 15 & M & 6 months & Ketoacidosis & 204 & 3 & 21 & 9 & 8 \\
\hline D8 & 18 & M & 4 months & Hypoglycaemia & 73 & 23 & 57 & 17 & 0 \\
\hline D9 & 23 & M & 2 weeks & Ketoacidosis & 103 & 12 & 65 & 6 & 0 \\
\hline D10 & 42 & $\mathrm{~F}$ & 18 months & $\begin{array}{l}\text { Glioma raised } \\
\text { intracranial pressure }\end{array}$ & 274 & 17 & 45 & 24 & 7 \\
\hline
\end{tabular}

F, female; ICI, insulin-containing islet; IDI, insulin-deficient islet; M, male.

anti-MCM-2 were detected on separate sections using the immunoperoxidase technique, while endocrine cells and lymphocytes were detected using immunofluorescence. After counterstaining with haematoxylin, Ki67 immunoperoxidasestained sections from donors with recent-onset type 1 diabetes and from the non-diabetic controls were incubated with primary antibodies against either insulin and glucagon, or insulin and somatostatin, or insulin and CD45, or glucagon and CD45. MCM-2-stained sections were further incubated with antibodies against insulin or CD45. Sections from chronic pancreatitis patients were further incubated in a cocktail of antibodies against insulin and glucagon. The antibodies were detected with goat AlexaFluor 488 or 568 conjugated secondary antibodies (Invitrogen, Paisley, UK). DAPI (1:1,000; Invitrogen) was included in the final secondary incubation to stain cell nuclei. By this method, tissue from nine of the ten deceased type 1 diabetic patients was found to be suitable for analysis; the tissue from the one other patient failed to absorb the DAPI nuclear stain. Sections were mounted in Vectashield hard-set mounting medium (Vector Laboratories, Peterborough, UK) under glass cover slips.

The sections were analysed initially using the brightfield function of a microscope (Eclipse 80i; Nikon, Kingston-
upon-Thames, UK) and a monochrome photomicrograph was captured for each islet that contained at least one Ki67+ cell. The fluorescence imaging function of the microscope was then used to capture immunofluorescence staining. The images were precisely overlaid using NIS-Elements BR 3.0 software (Nikon) to determine the endocrine cell sub-type of the $\mathrm{Ki} 67+$ or MCM-2+ cells.

Staining analysis Islets were identified morphologically in each pancreas section after counterstaining with haematoxylin. Initially all islets on each section from every donor were assessed for the presence of Ki67+ or MCM-2+ nuclei, and the percentage of islets containing one or more immunopositive cells per section was recorded. Using the combination imaging technique described above, the identity of each of the cells with Ki67+ nuclei was determined. In islets infiltrated with immune cells (which could be readily identified by their unique morphology), any Ki67+ cell that was evidently an immune cell was excluded from the analysis. A Ki67 labelling index was determined for alpha and beta cells in the non-diabetic control and type 1 diabetic donor groups according to the percentage of each islet cell type that was positively stained
Table 2 Details of primary antibodies used

\begin{tabular}{lllll}
\hline Antigen & Cell type & Species & Dilution & Source \\
\hline Ki67 & Proliferating & Mouse & $1: 200$ & Dako, Ely, UK \\
MCM-2 & Proliferating & Rabbit & $1: 2,000$ & Abcam, Cambridge, UK \\
Insulin & Beta & Guinea pig & $1: 600$ & Dako \\
Glucagon & Alpha & Rabbit & $1: 300$ & Dako \\
Somatostatin & Delta & Rabbit & $1: 200$ & Abcam \\
CD45 & Lymphocytes & Mouse & $1: 750$ & Dako \\
\hline
\end{tabular}


for Ki67. Cell counting was carried out using Adobe Photoshop CS4 software (Adobe, Uxbridge, UK). Islets were categorised as insulitis-positive if there were five or more CD45+ cells within the islet perimeter [14].

Statistical analysis The percentage of Ki67+ or MCM-2+ islets per section is expressed as the mean \pm SEM and statistical significance was calculated by Student's $t$ test using SPSS 16 software (SPSS, Chicago, IL, USA). The statistical significance of differences in the labelling index of islet cells and also the insulitis correlation were calculated using $\chi^{2}$ analysis.

\section{Results}

The percentage of islets with Ki67-positive islet cells was increased in recent-onset type 1 diabetic donors compared with non-diabetic controls For the initial analysis, one pancreas section from each of ten recent-onset type 1 diabetic donors and the 14 age-matched non-diabetic controls was stained with an anti-Ki67 antibody and the percentage of islet sections with at least one Ki67+ nucleus was calculated. A mean $( \pm \mathrm{SEM})$ of only $1.1 \pm 0.3 \% \mathrm{Ki} 67+$ islets per pancreas section (range $0-1.5 \%$ ) was recorded in the non-diabetic controls. This number was increased by more than tenfold in the recent-onset type 1 diabetic group to $10.9 \pm 2.5 \%(p<0.005)$ of islets per section (range $1.5-$ $31.8 \%$; Fig. 1a, Table 3). A typical Ki67+ islet from a type 1 diabetic donor is shown in Fig. $1 \mathrm{~b}$.

Overall, 1,280 and 4,031 islet sections were examined in the type 1 diabetic and control groups, respectively. In the type 1 diabetic group, a mean of $37.1 \pm 8.2 \%$ (range $6.7-$ $78.4 \%$ ) of the total islet sections were insulin-positive. Of the islet sections that were $\mathrm{Ki} 67+, 23 \%$ were insulinnegative, suggesting that the increased proliferation was not restricted solely to beta cells. The mean area $( \pm \mathrm{SEM})$ per

a

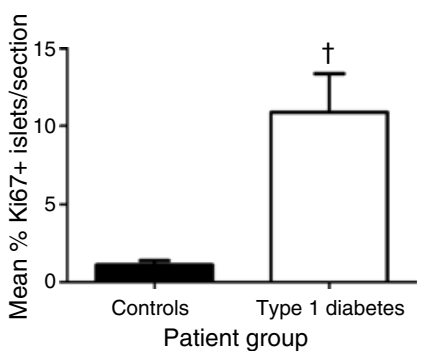

Fig. $1 \mathrm{Ki} 67+$ islet cell staining. a Mean percentage of islets per section with $\geq 1 \mathrm{Ki} 67+$ cells in recent-onset type 1 diabetic and in nondiabetic control donors; ${ }^{\dagger} p<0.005$. b Photomicrograph of Ki67+ cells (brown, arrows) in an islet from a type 1 diabetic donor. Counterstaining with haematoxylin is in purple. Scale bar, $20 \mu \mathrm{m}$ islet was calculated for the recent-onset type 1 diabetic donors and the non-diabetic controls. These values were $18,227 \pm 1,054 \mu^{2}$ for insulin-positive and 9,017 \pm $1,139 \mu \mathrm{m}^{2}$ for insulin-negative islets in the type 1 diabetic group, and $12,265 \pm 1,095 \mu^{2}$ for insulin-positive islets in the non-diabetic controls (all islets were insulin positive in this group).

The increase in Ki67+ islet cells in recent-onset type 1 diabetes occurs in alpha and beta cells To determine which islet cells produced Ki67 in recent-onset type 1 diabetes, sections from nine donors were analysed in greater detail. Each section was co-stained with anti-Ki67 (immunoperoxidase) and combinations of anti-insulin, anti-glucagon and anti-somatostatin (immunofluorescence). The sections were photomicrographed under brightfield illumination to capture images of the islets containing at least one $\mathrm{Ki} 67+$ islet cell. Fluorescence images of the staining patterns of insulin, glucagon and somatostatin were captured subsequently and the images overlaid (Fig. 2a-g, ESM Figs 1 and 2).

The Ki67 labelling index was $0.006 \%$ for alpha cells and $0.008 \%$ for beta cells in the sections from control donors. The labelling index of both cell types increased significantly in the recent-onset type 1 diabetic group to $0.066 \%$ (alpha cells) and $0.07 \%$ (beta cells), respectively ( $\chi^{2} p<0.001$; Fig. 3). The number of Ki67+ delta cells was insufficient to allow accurate quantification of a labelling index.

The topography of the staining patterns precluded unequivocal identification of $10 \%$ to $20 \%$ of the $\mathrm{Ki} 67+$ islet cells, both in the recent-onset type 1 diabetic pancreatic sections and in the non-diabetic controls.

Increased proliferation of islet cells in type 1 diabetes was also seen using a second marker of cell proliferation Ki67 is a widely used marker of cell proliferation. However, it was considered important to confirm the presence of proliferating cells with a second proliferation-specific protein, unrelated to Ki67. MCM-2 was chosen for this purpose and pancreas sections from the ten type 1 diabetic and 14 non-diabetic control donors were stained with an anti-MCM-2 antibody using the immunoperoxidase technique. In the control group, a mean $( \pm \mathrm{SEM})$ of $2.4 \pm 0.5 \%$ (range $0-7.1 \%$ ) islets per section had at least one MCM-2+ cell. This was a statistically higher percentage than that found with the Ki67 antibody in the same group $(p<0.05)$, possibly reflecting the longer period of production of MCM-2 vs Ki67 during the cell cycle, as revealed by the staining patterns seen with these markers in tonsil epithelium (ESM Fig. 3). In this tissue, the oral mucosa cells divide at the base of the stratified squamous epithelium and migrate towards the surface after division. MCM-2+ cells 
Table 3 The mean percentage of Ki67+ islets detected in the donor groups

\begin{tabular}{llll}
\hline Donor group & Patients $(n)$ & Islets examined $(n)$ & $\%$ Ki67+ islets $(\mathrm{mean} \pm \mathrm{SEM})$ \\
\hline Non-diabetic controls (C1-C14) & 14 & 4,031 & $1.1 \pm 0.3$ \\
Recent-onset type 1 diabetes & 10 & 1,280 & $10.9 \pm 2.5^{\mathrm{a}, \mathrm{b}}$ \\
Long duration type 1 diabetes & 3 & 561 & 0 \\
Type 2 diabetes & 10 & 1,436 & $1.5 \pm 1.6^{\mathrm{c}}$ \\
Non-diabetic controls (C40-C48) & 9 & 3,078 & $0.97 \pm 0.37^{\mathrm{e}}$ \\
\hline
\end{tabular}

${ }^{a}$ Significantly greater than non-diabetic controls $(p<0.005)$

${ }^{\mathrm{b}}$ Significantly greater than type 2 diabetes donors $(p<0.005)$

${ }^{\mathrm{c}}$ Not significantly different from non-diabetic controls $(p=0.55)$

d Age-matched with type 2 diabetic donors

${ }^{\mathrm{e}}$ Not significantly different from type 2 diabetic donors $(p=0.5)$

were detected further from the dividing layer than those stained with Ki67, consistent with the longer persistence of MCM-2 after mitosis. Staining of sections from the type 1 diabetic group confirmed a marked increase in the rate of proliferation of islet cells (to $11 \pm 2.6 \%$ of islets (range 5.3-29.3\%); $p<0.001$ vs control; Fig. 4a). A representative islet section stained positively for MCM-2 is shown in Fig. 4b.

Pancreas sections from three of the ten recent-onset type 1 diabetic donors were double-stained with anti-MCM-2 and anti-insulin in order to assess the percentage of MCM-2+ beta cells. In the 54 MCM-2+ islets examined, $142 \mathrm{MCM}-2+$ cells were detected. Of these, $60(42 \%)$ were dual-positive for insulin, thereby confirming that they were beta cells (Fig. 4c, d).

To confirm that the majority of MCM-2+ cells were islet cells rather than infiltrating lymphocytes, dual staining was performed with anti-MCM-2 and anti-CD45. We examined in detail $21 \mathrm{MCM}-2+$ islets that were heavily infiltrated with CD45+ lymphocytes. Very few of the infiltrating CD45+ cells were co-positive for MCM-2 (Fig. 4e). Peripancreatic lymph nodes were often present adjacent to the pancreas sections, and dual staining revealed the presence of $\mathrm{MCM}-2+\mathrm{CD} 45+$ cells, demonstrating that immunoperoxidase staining of the nucleus with anti-MCM2 had not interfered with the ability of the CD45 antibody to stain the lymphocyte cell surface (Fig. 4f).

The presence of Ki67+ islet cells correlates with insulitis in type 1 diabetes Pancreas sections were stained to assess the relationship between insulitis and Ki67-positivity in islet cells. Insulitis was defined as the presence of five or more CD45+ lymphocytes within the islet perimeter [14]. We examined 1,091 islet sections from eight type 1 diabetic donors and 247 of these $(22.6 \%)$ were insulitis-positive. In this group, 44 of 247 islets (17.8\%) contained one or more Ki67+ islet cell. Of these, 42 were also insulin-containing islets. By contrast, only 22 of the 844 insulitis-negative islets (2.6\%) contained a Ki67+ islet cell. Of these 22 islets, seven were insulin-containing (Fig. 5a, b). Thus, there was a sevenfold increase in the frequency of Ki67+ islet cells detected in islets containing infiltrating immune cells compared with islets that were insulitis-negative $\left(\chi^{2} p<\right.$ $0.001)$. To verify this conclusion, we also compared the proportion of insulin-containing islets that were Ki67+ and inflamed (42 of 405 [10.4\%]) with those that were Ki67+ but not inflamed (7 of 405 [1.7\%]). This large difference is consistent with the proposition that proliferation correlates with the inflammatory response. Additional support was obtained by direct comparison of the Ki67 labelling index for Ki67+ and insulin+cells in inflamed vs non-inflamed islets, which yielded significantly different values of $0.097 \%$ and $0.004 \%(p<0.0005)$, respectively (Fig. 5 c).

Increased Ki67+ labelling of islet cells was not maintained in donors with longer duration type 1 diabetes To establish whether the increase in proliferating islet cells is persistent, pancreatic sections from three type 1 diabetic donors with a longer disease duration (one 6, two 12 years) were stained with the anti-Ki67 antibody. One of these donors (disease duration 12 years) still retained some residual beta cells in 53 of 79 of their islet sections; the other donors were entirely beta cell-deficient in the available sections. No $\mathrm{Ki67+}$ islet cells were detected in any of the 561 islet sections examined in these donors (Table 3).

Increased Ki67+ labelling of islet cells was not observed in donors with type 2 diabetes To determine whether the increase in islet cell proliferation was restricted to patients with (recent-onset) type 1 diabetes, pancreatic sections from ten donors with type 2 diabetes were also stained with the Ki67 antibody. Examination of 1,436 islets revealed that the mean $( \pm \mathrm{SEM})$ percentage of Ki67+ islets per section $(1.5 \pm$ $0.16 \%$; three donors had no Ki67+ cells) was statistically lower than that of the recent-onset type 1 diabetic group $(p<0.005)$, but not different from the non-diabetic controls 

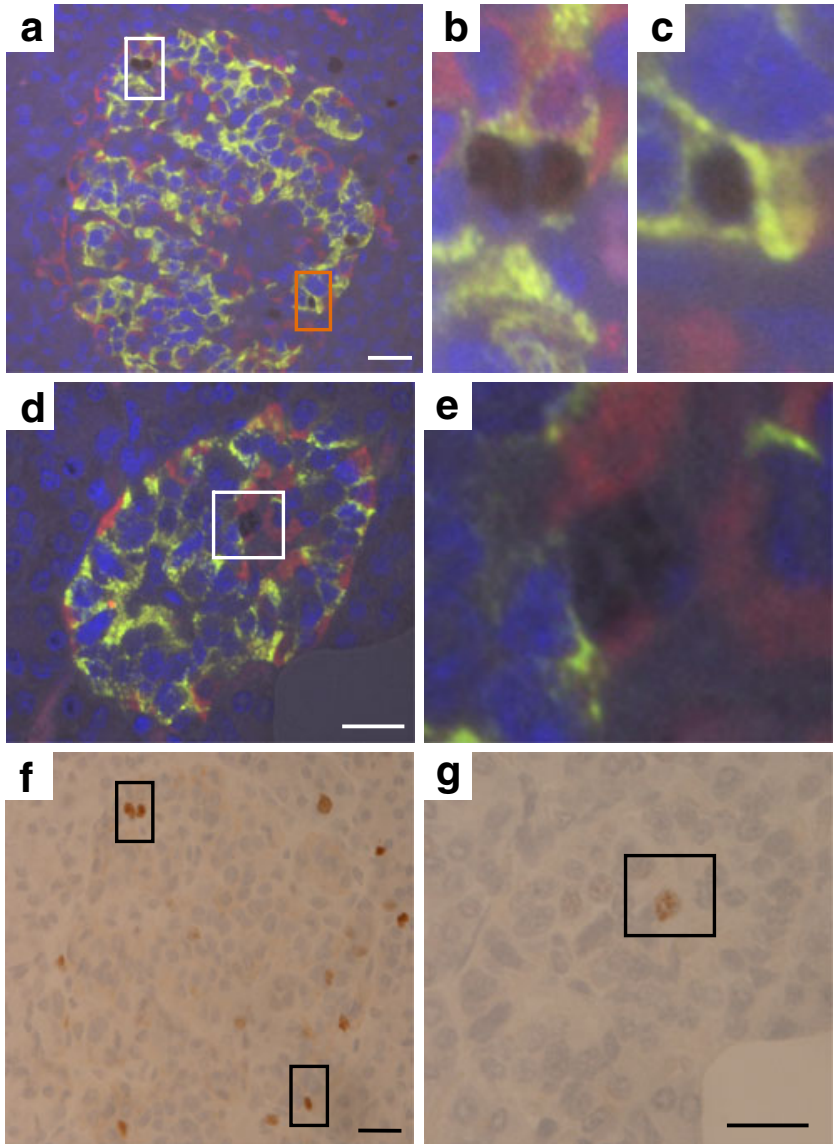

Fig. 2 Photomicrographs of islets from type 1 diabetic donors stained using the combination technique to determine the cell type of the Ki67+ nuclei. a An islet showing insulin (green), glucagon (red) and Ki67 (dense black nuclei). White and orange boxes highlight areas seen in respective magnified images (b, c), which demonstrate Ki67+ and insulin+ cells indicative of proliferating beta cells. d An islet showing insulin (green), glucagon (red) and Ki67 (dense black nuclei). White box highlights the area in magnified image (e), which indicates a Ki67+ alpha cell. a-e Cell nuclei were stained with DAPI (blue). f A brightfield image of the islet shown above (a). Ki67+ nuclei are visible in brown; counterstaining with haematoxylin is in purple. Black boxes highlight the two areas shown above $(\mathbf{b}, \mathbf{c})$. g A brightfield image of the islet shown above (d). The black box highlights the nucleus in the image above (e). Scale bar, $20 \mu \mathrm{m}$

$(p=0.55$; Table 3$)$. Samples from the type 2 diabetic donors were also compared with those from nine agematched non-diabetic controls stained for Ki67. In this control group a mean of $0.97 \pm 0.37 \%$ islets per section contained Ki67+ cells, which was not statistically different from the type 2 diabetic donors $(p=0.5$; Table 3$)$.

Increased Ki67+ labelling of islet cells was not observed in donors with pancreatitis Since the increased proliferation detected in patients with recent-onset type 1 diabetes correlated with immune cell infiltration, it was important to examine the pancreas of patients with a different inflammatory disease of the pancreas, pancreatitis. Accord-

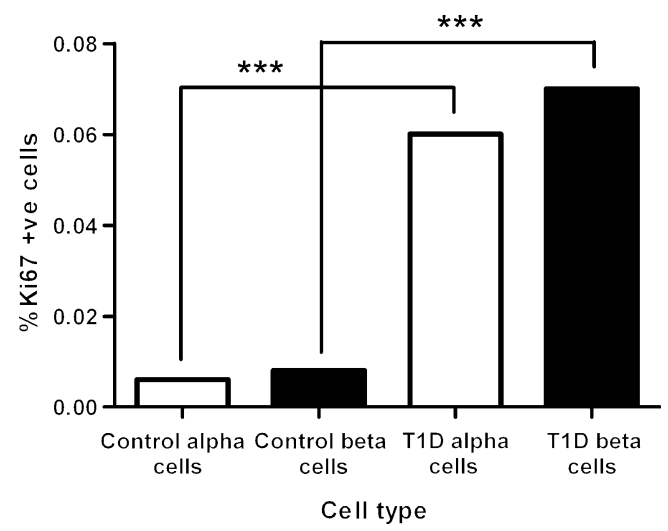

Fig. 3 Ki67 labelling index for alpha and beta cells. Bars show the percentage of total $\mathrm{Ki} 67+$ alpha and $\mathrm{Ki} 67+$ beta cells in the nondiabetic control and the recent-onset type 1 diabetic donor groups as indicated. $* * * p<0.001$

ingly, pancreatic sections from 12 donors with either chronic, autoimmune or obstructive pancreatitis were stained using the combination technique for Ki67, insulin and glucagon. Of the 12 samples analysed (2989 islets in total), three contained no Ki67+ cells within islets. In the remaining nine sections, 82 of 2,651 islets examined contained a total of $139 \mathrm{Ki} 67+$ cells. Of these, 42 were identified as endocrine cells (14 alpha, 26 beta); 99 were non-endocrine cells (Fig. 6a-c). In these samples no attempt was made to study small clusters of endocrine cells associated with pancreatic ducts.

\section{Discussion}

The rate of islet endocrine cell proliferation in humans varies with age. A wave of proliferation occurs early in postnatal life as the endocrine pancreas is released from the intrauterine environment and is remodelled to meet the demands of independent living and changing nutrition [3]. This period, however, is short-lived and is followed by a rapid decline in the proliferation rate; this then stabilises at an extremely low level, which is maintained throughout childhood and into adult life. A similar situation may also pertain in other mammalian species, although, in some species, islet cell proliferation can be re-induced during adulthood by the imposition of increased metabolic demand (e.g. during obesity) and also in response to the hormonal adaptations associated with pregnancy [6, 7]. Importantly, we have now demonstrated that islet cell proliferation is increased in humans during the ongoing process of insulitis and autoimmunity associated with the recent onset of type 1 diabetes.

To study the proliferation of islet cells, we employed immunohistochemical detection of two independent proteins produced uniquely during cell division. Ki67 is widely 
a
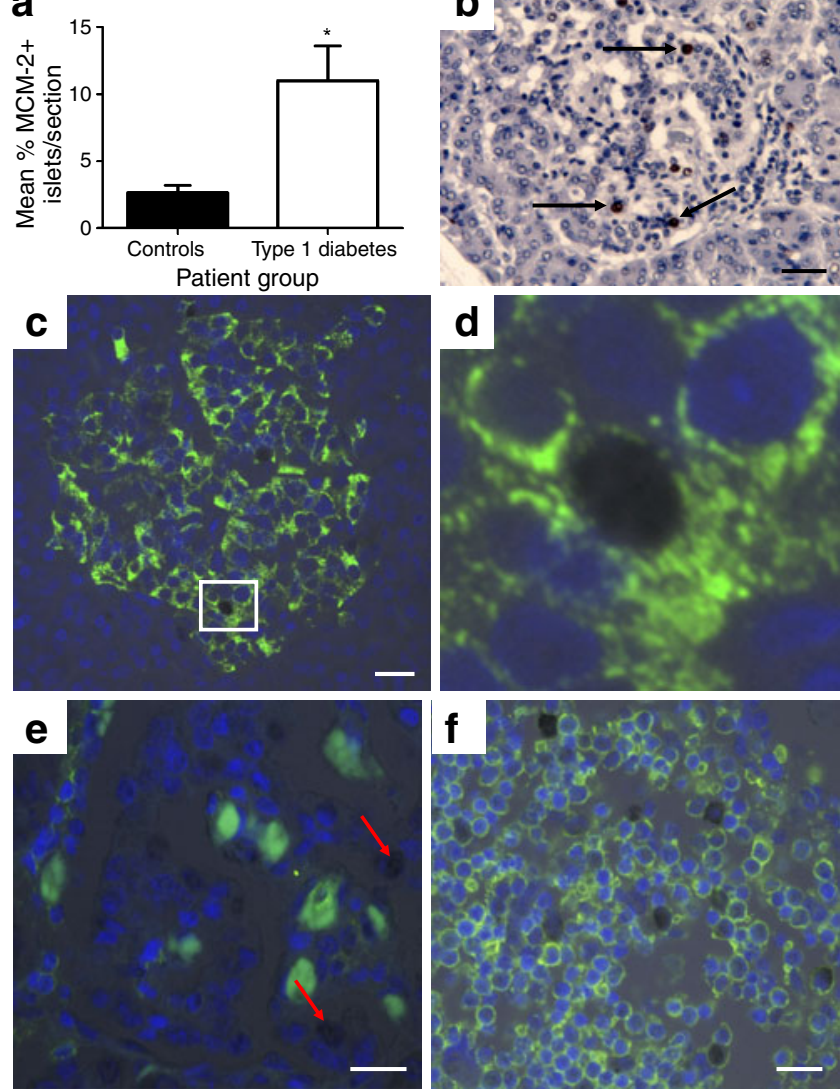

Fig. $4 \mathrm{MCM}-2+$ islet cell staining. a Mean percentage of islets per section with $\geq 1 \mathrm{MCM}-2+$ cells in type 1 diabetic and non-diabetic control donors; $* p<0.05$. b Photomicrograph demonstrating the presence of MCM-2+ cells (black arrows) in an islet of a type 1 diabetic donor. c Combination staining of MCM-2 (dense black nuclei) and insulin (green), indicating the presence of proliferating beta cells in a type 1 diabetic donor. White box highlights the area magnified (d), which shows a MCM-2+ insulin+ cell. e The combination technique was used to stain type 1 diabetic samples for MCM-2 (dense black nuclei indicated by red arrows) and CD45 (green) to demonstrate that the increased number of MCM-2+ nuclei in the type 1 diabetic vs control samples was not due to lymphocyte staining. f Staining of a pancreatic lymph node on the same section as a previous image (e) demonstrates that the MCM-2 immunoperoxidase staining did not disrupt the cells ability to also stain positively for CD45. Scale bars, $20 \mu \mathrm{m}$

used as a marker of cell division in fixed tissue, as it is expressed specifically during all stages of the cell cycle, but is degraded before cells re-enter gap $(\mathrm{G}) 0$ [15]. MCM-2 plays a role in DNA replication and is produced from early G1 through the remaining phases of the cell cycle, but is degraded prior to entry into G0 [16]. We analysed both proteins and found that they were detected at higher frequency in the nuclei of islet cells from donors with recent-onset type 1 diabetes than in those from non-diabetic controls. Detailed analysis revealed a tenfold increase in the proportion of islets displaying one or more Ki67+ cells in the type 1 diabetic samples vs controls. The increase was somewhat lower when the labelling of MCM-2 was assessed (approximately fivefold), but remained statistically significant. The reduction in the magnitude of the response seen when assessing MCM-2 was principally due to the larger proportion of islet sections from control donors that displayed MCM-2 immunopositivity compared with those that were positive for Ki67. This difference may reflect the different periods of the cell cycle when each protein is produced. Analysis of islet cells from islets of donors with recent-onset type 1 diabetes that displayed increased proliferation revealed that the labelling index of alpha and beta cells for Ki67 was enhanced by approximately tenfold. Thus, unlike the process of immune-mediated islet cell destruction (which is entirely beta cell-specific), the proliferative response appears not to display such cell specificity.

The increase in islet cell proliferation correlated closely with the presence of insulitis suggesting that a signal or signals emanating from infiltrating immune cells might mediate the enhanced proliferative response. Consistent with this hypothesis, an increase in islet cell proliferation has also been reported in the inflamed islets of a patient classified as having 'pre-diabetes' [8]. In addition, an 89year-old man recently diagnosed with type 1 diabetes, had increased Ki67+ islet cells, as well as insulitis in a large percentage of islets [17]. Taken together, these results support the suggestion that human islet cell proliferation can be increased during islet inflammation. Our finding that patients with a long duration of diabetes do not display islet cell proliferation also supports this conclusion, since islet inflammation was minimal in these patients.

Additional support for the possible involvement of immune-derived signals as mediators of islet cell proliferation comes from the NOD mouse and the BioBreeding rat. In the NOD model of diabetes, beta cell proliferation is increased during the prediabetic phase, a finding attributed to the presence of insulitis in the relevant islets $[9,10]$. The BioBreeding rat also has a higher than normal islet cell Ki67 labelling index during the prediabetic period when the islets are infiltrated by mononuclear cells [18]. Similar findings have also been reported in a partial pancreatectomy model in the LEW.Han rat [19], although, unlike our present findings in man, alpha cell proliferation was unchanged in these animals.

Examination of pancreatic sections from patients with pancreatitis, another inflammatory disease of the pancreas, revealed low numbers of Ki67+ alpha or beta cells, which is not consistent with a large-scale proliferative response. However, a significant increase in beta cell replication has been reported previously in sections from patients with severe pancreatitis, suggesting that, under these circumstances, the immune cells may elaborate a stimulus for endocrine cell proliferation [20]. One study has also 
a

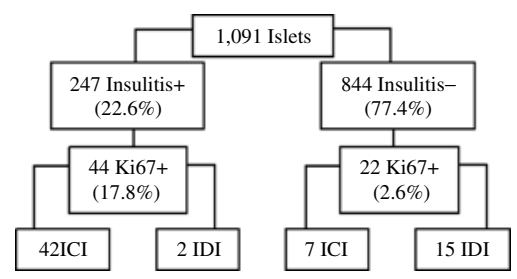

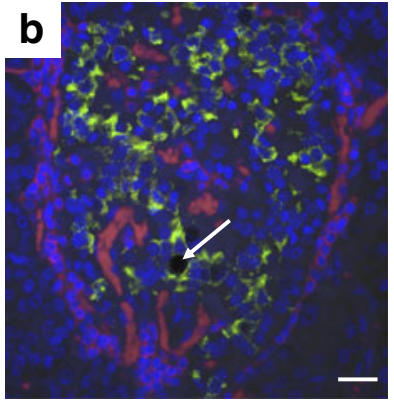

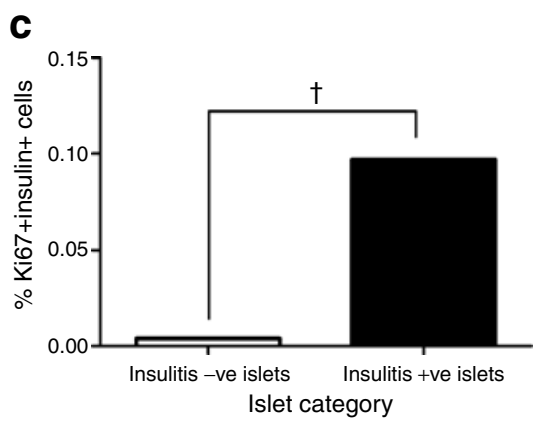

Fig. $5 \mathrm{Ki} 67+$ islets show a correlation with insulitis in type 1 diabetic patients. a Flow diagram showing the distribution of Ki67+ islets in pancreas sections from eight type 1 diabetic donors. Islets $(n=1,091)$ were divided into insulitis-positive or insulitis-negative. The number of $\mathrm{Ki67+}$ islets in each category was counted, totalling $66 \mathrm{Ki67+}$ islets. Ki67+ islets were subdivided into insulin-positive, i.e. insulincontaining (ICI) or insulin-negative, i.e. insulin-deficient (IDI) according to the presence or absence of positive insulin immunostain-

reported neogenesis of duct epithelial cells into insulinproducing cells in patients with chronic pancreatitis [21].

We did not characterise the nature of the putative immune cell-derived signal that may promote islet cell proliferation, but very low concentrations of certain proinflammatory cytokines (including IL-1 $\beta$ ) can elicit beta cell proliferation in isolated human islet preparations [22]. Higher doses of these same cytokines are cytotoxic, suggesting that the gradient of concentration to which islet cells are exposed may determine their ultimate fate. Conceivably, the initial influx of immune cells might promote endocrine cell proliferation, but this response may be ultimately overridden by a net cytotoxicity as the concentration of immune mediators increases further. It should, however, be noted that we did not detect an increase in Ki67+ islet cells in pancreas sections from donors with type 2 diabetes. This form of diabetes has
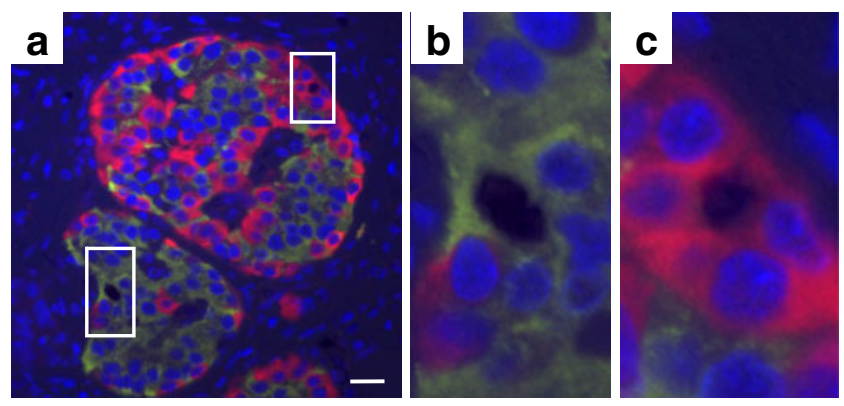

Fig. 6 A Ki67+ islet from a patient with chronic pancreatitis. a Photomicrograph showing insulin (green), glucagon (red), Ki67 (dense black nuclei) and DAPI (blue). b Magnification of region in lower white box (a). The green insulin staining is indicative of the black nucleus having a beta cell phenotype. c Magnification of region in upper white box (a). The red glucagon staining surrounding the black nuclei indicates that this nucleus has an alpha cell phenotype. Scale bar, $20 \mu \mathrm{m}$ ing. b Photomicrograph demonstrating the presence of insulitis in an islet stained for insulin (green), CD45 (red), DAPI for nuclei (blue) and Ki67 (dense black nuclei, white arrow) using the combination technique. Scale bar $20 \mu \mathrm{m}$. c Percentage of Ki67+ insulin-positive cells in insulitis-negative and insulitis-positive islets from recent-onset type 1 diabetic donors. The insulitis-negative group comprised 844 islets, the insulitis-positive group 247 islets. ${ }^{\dagger} p<0.0005$

recently been shown to be associated with low-level macrophage infiltration of the islets, but there is no lymphocyte infiltration $[14,23,24]$. This implies that a signal other than IL-1 $\beta$ (which is secreted by macrophages, but not by $\mathrm{T}$ or $\mathrm{B}$ lymphocytes) may be primarily responsible for mediating the proliferative response. The finding that islet cell proliferation is not increased in patients with type 2 diabetes also implies that hyperglycaemia is unlikely to represent a primary stimulus for the proliferative response, since this is a feature of both forms of the disease.

The present results differ from the recent findings of Butler et al. [12], who did not find any increase in beta cell proliferation in deceased patients with recent-onset type 1 diabetes. If, as we propose, the proliferative response reflects an early response to insulitis, then this may have been undetectable in several of the samples examined by Butler et al. [12], since four of the nine persons studied did not have insulitis. However, other undefined factors might also account for the differences.

In summary, the current study reveals that islet cell proliferation is increased in the islets of patients with recentonset type 1 diabetes. This correlates with inflammation and suggests that the immune cells elaborate a signal that promotes islet cell mitosis. These results suggest that, if mechanisms could be found to facilitate cell proliferation during the prediabetic phase, it might be possible to facilitate the regeneration of beta cells as a therapeutic intervention in patients progressing to type 1 diabetes.

Acknowledgements We are grateful to the Juvenile Diabetes Research Foundation for funding this study.

Duality of interest The authors declare that there is no duality of interest associated with this manuscript. 


\section{References}

1. Foulis AK (1996) The pathology of the endocrine pancreas in type 1 (insulin-dependent) diabetes mellitus. APMIS 104:161-167

2. Atkinson MA, Gianani R (2009) The pancreas in human type 1 diabetes: providing new answers to age-old questions. Curr Opin Endocrinol Diab Obes 16:279-285

3. Meier JJ, Butler AE, Saisho Y et al (2008) Beta-cell replication is the primary mechanism subserving the postnatal expansion of beta-cell mass in humans. Diabetes 57:1584-1594

4. Cnop M, Hughes SJ, Igoillo-Esteve M et al (2009) The long lifespan and low turnover of human islet beta cells estimated by mathematical modelling of lipofuscin accumulation. Diabetologia 53:321-330

5. Dhawan S, Georgia S, Bhushan A (2007) Formation and regeneration of the endocrine pancreas. Curr Opin Cell Biol 19:634-645

6. Sorenson RL, Brelje TC (1997) Adaptation of islets of Langerhans to pregnancy: beta-cell growth, enhanced insulin secretion and the role of lactogenic hormones. Horm Metab Res 29:301-307

7. Rieck S, Kaestner KH (2009) Expansion of beta-cell mass in response to pregnancy. Trends Endocrinol Metab: TEM 21:151-158

8. In't Veld P, Lievens D, de Grijse J et al (2007) Screening for insulitis in adult autoantibody-positive organ donors. Diabetes 56:2400-2404

9. Sreenan S, Pick AJ, Levisetti M, Baldwin AC, Pugh W, Polonsky KS (1999) Increased beta-cell proliferation and reduced mass before diabetes onset in the nonobese diabetic mouse. Diabetes 48:989-996

10. Sherry NA, Kushner JA, Glandt M, Kitamura T, Brillantes AM, Herold KC (2006) Effects of autoimmunity and immune therapy on beta-cell turnover in type 1 diabetes. Diabetes 55:3238-3245

11. Nir T, Melton DA, Dor Y (2007) Recovery from diabetes in mice by beta cell regeneration. J Clin Investig 117:2553-2561

12. Butler AE, Galasso R, Meier JJ, Basu R, Rizza RA, Butler PC (2007) Modestly increased beta cell apoptosis but no increased beta cell replication in recent-onset type 1 diabetic patients who died of diabetic ketoacidosis. Diabetologia 50:2323-2331

13. Meier JJ, Bhushan A, Butler AE, Rizza RA, Butler PC (2005) Sustained beta cell apoptosis in patients with long-standing type 1 diabetes: indirect evidence for islet regeneration? Diabetologia 48:2221-2228

14. Willcox A, Richardson SJ, Bone AJ, Foulis AK, Morgan NG (2009) Analysis of islet inflammation in human type 1 diabetes. Clin Exp Immunol 155:173-181

15. Gerdes J, Lemke H, Baisch H, Wacker HH, Schwab U, Stein H (1984) Cell cycle analysis of a cell proliferation-associated human nuclear antigen defined by the monoclonal antibody Ki-67. J Immunol 133:1710-1715

16. Todorov IT, Attaran A, Kearsey SE (1995) BM28, a human member of the MCM2-3-5 family, is displaced from chromatin during DNA replication. J Cell Biol 129:1433-1445

17. Meier JJ, Lin JC, Butler AE, Galasso R, Martinez DS, Butler PC (2006) Direct evidence of attempted beta cell regeneration in an 89 -year-old patient with recent-onset type 1 diabetes. Diabetologia 49:1838-1844

18. Bone AJ, Walker R, Dean BM, Baird JD, Cooke A (1987) Prediabetes in the spontaneously diabetic $\mathrm{BB} / \mathrm{E}$ rat: pancreatic infiltration and islet cell proliferation. Acta Endocrinol 115:447-454

19. Lampeter EF, Tubes M, Klemens C et al (1995) Insulitis and isletcell antibody formation in rats with experimentally reduced betacell mass. Diabetologia 38:1397-1404

20. Campbell-Thompson M, Dixon LR, Wasserfall C et al (2009) Pancreatic adenocarcinoma patients with localised chronic severe pancreatitis show an increased number of single beta cells, without alterations in fractional insulin area. Diabetologia 52:262-270

21. Phillips JM, O'Reilly L, Bland C, Foulis AK, Cooke A (2007) Patients with chronic pancreatitis have islet progenitor cells in their ducts, but reversal of overt diabetes in NOD mice by anti-CD3 shows no evidence for islet regeneration. Diabetes 56:634-640

22. Maedler K, Schumann DM, Sauter N et al (2006) Low concentration of interleukin-1beta induces FLICE-inhibitory protein-mediated beta-cell proliferation in human pancreatic islets. Diabetes 55:2713-2722

23. Ehses JA, Perren A, Eppler E et al (2007) Increased number of islet-associated macrophages in type 2 diabetes. Diabetes 56:2356-2370

24. Richardson SJ, Willcox A, Bone AJ, Foulis AK, Morgan NG (2009) Islet-associated macrophages in type 2 diabetes. Diabetologia 52:1686-1688 